\title{
Integrated Model for Teaching Language Skills
}

\author{
Amr Abdullatif Yassin ${ }^{1 \& 2}$, Norizan Abdul Razak ${ }^{1} \&$ Tg Nor Rizan Tg Mohamad Maasum ${ }^{1}$ \\ ${ }^{1}$ Faculty of Social Sciences and Humanities, Universiti Kebangsaan Malaysia, Bangi, Selangor, Malaysia \\ ${ }^{2}$ Centre of Languages and Translation, Ibb University, Ibb, Yemen \\ Correspondence: Amr Abdullatif Yassin, Centre of Languages and Translation, Ibb University, Yemen. E-mail: \\ amryassin84@gmail.com
}

Received: May 11, 2019 Accepted: June 10, 2019 Online Published: August 26, 2019

doi:10.5539/ijel.v9n5p89 URL: https://doi.org/10.5539/ijel.v9n5p89

\begin{abstract}
This paper suggests a new model to teach language skills. The aim of this model is to integrate the three most influential theories in the process of language teaching and learning which are behaviorism, cognitivism and constructivism. This model explains how these three theories are integrated with each other in the process of language teaching and learning to complete each other taking into consideration the strengths and weaknesses of each theory. This model is mainly used for teaching language skills which are reading, writing, speaking and listening. Reviewing previous literature, it is clear that there is no integrated model that has tried to link these theories although there are suggestions from scholars to integrate them in a single model because there is no theory that can describe the whole process of learning without the interference of the other theories. This model suggests that teaching any skill can be divided into two phases. The first one is introducing the skill theoretically and the second one is practice. The first phase requires constructivism in order to build the students' knowledge concerning the skill, and the second one is practice which depends on behaviorism through providing different drills to students. Cognitivism is the link between constructivism and behaviorism. Thus, creating knowledge is the core of constructivism but it is mentally driven as it requires cognitive processes. Also, behaviorism focuses on practice and it did not account for the cognitive processes which are essential especially because practice is associated with the mental activation of all the linguistic knowledge. Therefore, the paper discusses the three theories and the rational for the new model as well as the process of teaching following the suggested model.
\end{abstract}

Keywords: English Language Teaching, integrated teaching model, language skills, behaviorism, cognitivism, constructivism

\section{Introduction}

There are many theories that have been written about the process of language teaching and learning; however, every theory looks at this process from a specific perspective. This is not only in the field of education but also in the other fields like science. This led the researchers to combine different theories in order to have a comprehensive overview about some topics or phenomenon. The authors suggest integrated model in the field of language teaching and learning language skills which combines different theories and in which every theory completes the other theories in order to have a full picture for the process of language teaching and learning.

The beginning of learning theories was with behaviorism especially by Skinner in the middle of the 20th century in his book Verbal Behavior (1957). Skinner looked at the process of learning as a change in the behavior. Behaviorism received criticism from other scholars especially Chomsky who argued that behaviorism does not account for the innate ability of humans for language learning, and this is its weakness because humans have innate ability to learn the language, which he called Language Acquisition Device (LAD) (Brown, 2007).

The next theory is cognitivism which appeared in 1970s and which linked the process of learning to the mental processes or the non-observable constructs. Actually, cognitivism came as a reaction to behaviorism because learning cannot be achieved without the involvement of the mental processes of the learner (Xiangui, 2005).

Constructivism came as a reaction to the two previous theories because it looks at the process of learning as an interactive process between the person and the other people in the surrounding environment. The person builds his language through interaction with the others around him, and it is interaction with the others that leads to mastering language (Brown, 2007). 
Every theory from the above-mentioned theories looks at the process of language learning from a specific perspective, and there is not any talk about a universal theory or integrated model that can be taken as a comprehensive framework to explain the process of language learning. This paper combines these three theories in order to create an integrated model. The aim is to focus on the strengths and weaknesses of each theory in order to make the process of learning more fruitful. Also, there is a need to integrate these theories in one model because every theory is important in the process of language teaching and learning, and every theory is a complementary for the other theories.

The significant of the present model stems from the fact that theories are interconnected, and teachers cannot depend on one theory to teach language skills. This model explains the relationship between these three theories in teaching language skills. This makes the present model a suitable theoretical or conceptual framework for the researchers who are engaged in teaching language skills. This model gives the researcher a chance to provide a better explanation for teaching language skills. More importantly, this model might be a seed for coming efforts to write a comprehensive learning theory that gives a better and clear understanding for language learning under one theory.

Besides, students of English language in different parts of the world facing problems in language skills, and there is a need to introduce new teaching models that might help solve such problems. In addition, teaching requires reducing the gap between teaching and learning because students should not be in the position of recipient during the process of learning language skills (Nor, Azman, \& Hamat, 2013). Accordingly, there should be a balance between the input and the output in teaching and learning language skills, which calls for the need to have a model that takes such points into consideration and takes into account the strength of each learning theory in a practical way as such new models might help to improve teaching language skills.

\section{Literature Review}

This section will review the three theories related to the study namely behaviorism, cognitivism and constructivism.

\subsection{Behaviorism}

Behaviorism is associated with the efforts of Ivan Pavlov and Skinner, and it looks at learning as a habit formation. It depends on the process of stimuli-response-reinforcement and the relationship between these three factors (Hutchinson \& Waters, I987). In behaviorism theory, both the learner and environment are important, but the emphasis is on the environment. Students learn through building habits, but these habits are resulted from the stimuli which comes from the outside and its association with the responses of the learners. The role of the learner is passive in behaviorism as the learner is considered a receiver, and he does not take a role in discovering the environment surrounding him (Ertmer \& Newby, 2013). That is, there are two important elements in behaviorism which are the learner and the environment, but the emphasis is on the environment because the learner is a reactive to the surrounding environment. The role of the teacher is to decide when to begin the instruction and what type of reinforcement should be given to the learner.

According to Skinner in his book Verbal Behaviors (1957), learning a second or foreign language is a habit formation which the learners achieve through stimuli, response and reinforcement. The reinforcement can be positive or negative, and positive reinforcement is what learners need to improve their language. The process of stimuli, response and reinforcement helps in forming the habits of the learners since it is based on practice (Jordan, 2008).

Reward is an important principle of behaviorism since the reinforcement and reward help learners to build habit formation. If the learner does not receive reinforcement and is not encouraged, he might not be able to receive the adequate guidance in the process of language learning. Learners link between stimuli and responses, and this link is extended to the reinforcement and the support of the others to keep language practice. The main goal of reinforcement is to make it possible for certain habits to be repeated in the future, and this strengthens the process of learning. Thus, reinforcement encourages learners to repeat the same habits in the future since they help to improve learner's language; however, there is no attempt that has been made to explain the knowledge structure or the mental processes because stimuli-response-reinforcement cannot be explained away from the involvement of the mental processes (Brown, 2007). Accordingly, mental processes in behaviorism are marginalized because it does not account for the role of the mind in the process of building learning habits.

Besides, there is a connection between Contrastive Analysis Hypothesis and behaviorism in the idea of transfer. The main idea of Contrastive Analysis is that learning is easier when there are similarities between the first language and the target language. Students can transfer their first language knowledge to the target language 
practice if they discover similarities between the two languages (Lado, 1957). For example, native speakers of Arabic language, who study English as a foreign language, can take into consideration that there is a similarity between Arabic and English in the nominal sentence since the structure is usually subject, verb and object. However, they might encounter difficulties in the structure of adjectives and nouns because the order of adjectives and nouns differs in Arabic and English. Thus, the noun comes first followed by the adjective in Arabic, but it is the opposite in English.

\subsection{Cognitivism}

Cognitivism started in the late 1950s, and it became an influential learning theory in the 1970s, especially in instructional design. The beginning of this theory is tied with the cognitive evolution which was used in a broader context at the beginning and then used in the context of language learning (Mergel, 1998).

Cognitivism came as a reaction to behaviorism as it looks at the learner as an active participant in the process of language acquisition. Behaviors are not important here as the focus was shifted to what is going on in the black box of the mind, the memory, and the other psychological aspects of learning such as attitude, motivation and anxiety (Mergel, 1998). One of the opponents of this theory is Chomsky who argued that innate ability is the main motive for language learning, and behaviorism is a useless theory as it focuses on the response to the stimuli and neglected the innate ability of the learners to learn language (Xiangui, 2005). Therefore, the emphasis is changed from the overt observed behaviors to the unobservable process of language learning and acquisition especially in the 1950s. The mental processes such as information processing and problem-solving in language learning attracted the attention of researchers and scholars.

This new view of language learning looks at the learner as an individual whose mind processes all kinds of information such as language learning, which is a complex process, but it is still one of the processes happening in the learner's mind. Some of the processes which happen in the mind are choosing the appropriate vocabulary and using the correct grammatical rules, especially when using productive skills - speaking and writing (McLughlin, 1989).

The focus of cognitive theory is on learning conceptualization, and it investigates different aspects of language learning such as how information is received, organized, stored, transferred from short term memory to long term memory, and retrieved in the mind (Yassin, Razak, \& Maasum, 2018). According to Jonassen (1991), the concern of cognitivism is not on what learners do but on what learners know and how they could acquire it.

The principles of cognitivism are sensation, perception, attention, encoding, and memory which behaviorists did not take into consideration as these features are related to processes happening in the black box of the mind (Jordan, 2008). The first principle is sensation which looks at how the information is registered in sensors before sending them to the next level which is perception. Perception looks at how the learners make sense of the things which they perceive through senses. This include different processes which include pattern recognition, object recognition, bottom up or top down processing, and conscious perception. Attention refers to focusing on the most important thing from the view of the learners which requires high level of awareness. Encoding in cognitivism refers to the interpretation of the things which learners have perceived and paid attention to. Top down principle refers to how to transfer experience gained from the external world. The bottom up appears in the form of action based on prior knowledge, and it aims to help in the interpretation of the top down transfer of experience. The last principle is the mind which is the ability to keep knowledge in the mind, and it includes short-term memory and long-term memory (Jordan, 2008).

\subsection{Constructivism}

Constructivism came as a reaction to the two previous theories if we take into consideration their view to the source of knowledge. That is, in behaviorism and cognitivism, there is objectivity as the source of knowledge is external. This creates a need to look at the role of the individual in creating meaning or his own knowledge, and this is the main assumption of constructivism (Jonassen, 1991). Experience, therefore, is an important element in the process of language learning since it gives the learner the ability to create his own knowledge through his own experience.

There are two variations of constructivism. The first one is by Piaget which is the individual or cognitive constructivism. Piaget and Inhelder (1969) believe that the essential element of learning is discovery which depends on the role of the individual. Vygotsky (1978) sees that the focus of Piaget is on the internal processes which are related to the individual. He believes that there are other elements which are important for learning, and these elements are the cultural, historical and social interactions. Therefore, he added other elements which 
are external to the learner, and he became the pioneer of the second variation of constructivism known as socio-constructivism.

Students can create knowledge whether they have previous knowledge or not. To put it simply, if learners have previous knowledge, they will build the perceived knowledge and link it to the previous knowledge. Also, learners might not have previous knowledge, so they need to create their own understanding even if what they receive is inconsistent with what they have gained before (Hoover, 1996). These two notions keep learners active during the whole process of learning (Mvududu \& Thiel-Burgess, 2012).

Learners in constructivism are active participants and they create their own understanding. This makes the role of teacher like the guide who helps students to test their current understanding or come across new experiences to create their own knowledge. This puts the teacher in a challenge concerning the realization of learners' current knowledge in order to help them to put it in the forefront and apply it in new situations to created new knowledge. The teacher should create new learning contexts to build students' knowledge, taking into consideration that learners have different understanding abilities. However, the main role of the teacher is to engage students with learning environments to help them create their own understanding (Hoover, 1996).

Knowledge in constructivism is built up and it is evolved with the passage of time. The more the learner interacts with the others in different situations, the better his knowledge will be as it extends with experience. The focus of constructivism is not on a specific concept, but it is on how to help learners assemble knowledge from different sources. Negotiations and interactions help to accumulate the knowledge of learners, and it is of great asset to get a better interpretation for the task or the problem in hand (Spiro, Feltovich, Jacobson, \& Coulson, 1991).

The cognitive tools in constructivism are considered a reflection for wisdom of the culture and the experiences of the individual. The success of the learner, according to constructivism, depends on three tools which work together. The first one is the activity of the learner as real experiences shape his knowledge and help him to expand the circle of the existing knowledge. The second one is culture or the context which shows the relationship between the environment and the individual since engagement with others helps to build knowledge. The third one is knowledge itself because the aim of engagement with others is to build the concept in hand (Ertmer \& Newby, 2013).

\section{Rationale for the Integrated Teaching Model}

Xiangui (2005) concluded that there is a need for an integrated model that links between the common learning theories namely behaviorism, cognitivism and constructivism because there is not a comprehensive theory that accounts for the whole process of learning. Every theory looks at language learning from a specific perspective and the integration will help to provide a comprehensive picture for language learning.

If we look at every theory separately, we can find that everyone came as a reaction to previous theories to overcome existing weaknesses. Behaviorism concentrates on the verbal behavior; however, Chomsky (1959) criticized this point of view, and he asserts that there is an innate ability that enables humans to learn language. The natural ability of the person to learn language is absent in behaviorism which is one of its weaknesses. Thus, learning language is not due to the stimuli and response, but it is due to a special ability created in human beings, and behaviorism did not discuss the mental processes of language learning which are axiomatic in the process of learning.

In addition, cognitivism came as a reaction to behaviorism, and it concentrates on the mental processes associated with language learning. This can explain the necessity to link behaviorism and cognitivism because this will link building habits with the mental processes of learning.

Although cognitivism talked about communication and collaboration, it did not account for the practice of these principles in the classroom which shows a gap between the theoretical and practical sides in this theoretical perspective (Xiangui, 2005). Moreover, cognitivism focuses on non-observed explanations for the process of learning which leaves many questions because non-observed behaviors cannot be proved scientifically. According to Skinner, only the external stimuli-response can be studied because they can be approved scientifically unlike the point of view of cognitivism according (McLeod, 2015). The link, therefore, between behaviorism and cognitivism might redeem this gap because the external measures are a reflection for the internal processes of the stimuli-response. In other words, language learning in general and language skills learning can be understood better with the link between these two theories.

Besides, constructivism focuses on learners and their abilities to create meaning from what they receive, which might have some limitations in its application inside the classroom. That is, exposing students to knowledge 
partially will not help them to construct a representation as students of all ages and with different abilities can construct a representation if they are exposed to adequate knowledge (Kirschner, Sweller, \& Clark, 2006). Taking into consideration the different abilities of students makes it difficult to engage every student in activities that suit his abilities and understanding. Moreover, constructivism provides a good descriptive account for learning, but it does not lead to good prescriptive instructional methods of learning (Clark \& Estes, 1998, 1999; Estes \& Clark, 1999; Kirschner, Martens, \& Strijbos, 2004) as cited in (Kirschner, Sweller, \& Clark, 2006). Accordingly, constructivism is an insufficient perspective to explain the process of language learning. The creation of context for the class in general or for individual students is a kind of stimuli which requires the engagement of students. This shows that constructivism has a relationship with behaviorism in its application inside the classroom when teaching language skills. In addition, the main difference between constructivism and behaviorism is that constructivism looks at the ability of the learners to create meaning from what they receive while behaviorism focuses on what the instructor gives to the learners to improve their skills (Weegar \& Pacis, 2012). Many educators tried to link these two theories in the process of teaching as every theory completes the other if this point is taken into consideration (Weegar \& Pacis, 2012). Linking between the instructional goals of behaviorism and those of constructivism enables learners to improve their skills according to the input of the instructor which is related to behaviorism, and they can create meaning or discover meaning from that input depending on themselves at the same time which is related to constructivism.

Moreover, constructivism and cognitivism cannot be separated in the process of language learning. Constructivism looks at what the learner receives while cognitivism looks at how the learner processes what he receives (Ertmer \& Newby, 1993); however, there is still a link between the two theories because the meaning is mentally driven. This again shows that it is difficult to depend on behaviorism without the interference of constructivism in the process of language teaching and learning.

The above discussion shows that there is not one theory that can fully describe the process of language learning in general and language skills in particular. Every theory is interlaced with the other theories as there is not crystal-cut boundaries between the three theories. Therefore, there is a need to create a model to teach language skills taking into consideration the connection between the three theories as the concentrating on the strength of each theory will make the teaching of language skills more productive.

From the teaching perspective, there is a need to stimulate students to generate output in balance with providing the required input (Funk, 2012). Teaching should not be pragmatic only and lacks the presence of theoretical significance (Allison, 2004). Developing a comprehensive teaching model that takes such points related language teaching and learning will help to give a better understanding for the process of teaching and helps to make language learning more effective.

To sum up, behaviorism, cognitivism and constructivism look at the process of language learning from different perspective; nevertheless, there is a link between these theories since every theory completes the other theories. Behaviorism focuses on the stimuli-response-reinforcement and neglected the mental processes; therefore, the link between behaviorism and cognitivism will shift the focus to both the stimuli-response-reinforcement processes and the mental processes that underlie the interaction between the stimuli-response-reinforcement. Also, the assessment for the stimuli-response-reinforcement can be perceived as an assessment for the mental processes which are difficult to be assessed because they are covert. In terms of the relationship between cognitivism and constructivism, the creation of meaning in constructivism is cognitively driven, so these two theories cannot be separated. Besides, the link between constructivism and behaviorism during the process of learning helps the learners to create meaning, as stated by constructivism, and improve their skills, as stated by behaviorism, simultaneously. There is, therefore, a need to integrate these three theories to have a full picture for the process of language teaching and learning.

\section{Integrated Teaching Model and Interaction}

The suggested theories that are the basic of the integrated teaching model are constructivism, cognitivism and behaviorism. There is a link between all these theories which is interaction. In constructivism, the learner needs interaction with the others in order to construct concepts and knowledge. The surrounding environment is a very important element in the process of learning language. This is consistent with ZPD of Lev Vygotsky which explained that the learner might reach to the upper end if he depends on the others (Jordan, 2008). In other words, the learner who depends on him might reach to the lower end; however, with the help of the others, like teachers or other classmates, the learner will be able to reach to the upper end and foster the process of learning (Brown, 2007). Creating meaning through experience is the essential principle of constructivism, and the experience is usually achieved through engagement with the others. The learner according to constructivism does not acquire 
knowledge but rather creates it or builds it depending on interpretation (Spiro, Feltovich, Jacobson, \& Coulson, 1991). Knowledge, hence, is not instanteous but it is built through experience and accumulated with the passage of time, and interaction is the main tool in this process.

Cognitivism looks at the processes which happen in the black box of the mind. It focuses on knowledge processing and its transformation from the short-term memory to the long-term memory (Jordan, 2008). If we look at it from this perspective, practicing the language is essential to improve the learner's mental language abilities. For example, at the beginning of language learning, learners find it difficult to transform the knowledge of the language into output in a fast manner. Learners usually stammer and think in the native language before they speak in the target language. Learners at this stage work in different levels as they want to think of the words, pronunciation and the structure of the sentence. With practice, the cognitive abilities of students improve, and eventually they will find themselves able to produce the output in a good pace without thinking in the mother tongue. This happens in both the productive skills and the receptive skills as well. The process of thinking in speaking, reading or even writing and listening becomes in the target language instead of the native language which shows the improvement in the cognitive processes of learners. Looking at the process from this perspective makes interaction essential in improving the cognitive abilities of learners so that they will be able to produce the target language easily. Moreover, during the process of interaction learners might confirm some pieces of information in their minds or find themselves in a cognitive conflict with the others in a social situation (Mugny \& Doise, 1978). In both cases, the process of learning is fostered because confirming pieces of information makes the learner more confident in his own knowledge, and this helps to transform pieces of information from the short-term memory to the long-term memory. Similarly, when learners find themselves in a cognitive conflict with the others, and they might gain some corrections of which they become more aware. The reinforcement in cognitivism aims to help learners make proper mental connection between what they have learned. Reinforcement in constructivism does not aim to encourage behaviors to recur a certain practice in the future; instead, it aims to help learners link between different parts of knowledge in the mind in order to improve the cognitive process of language learning (Thompson, Simonson, \& Hargrave, 1992).

Besides, behaviorism is not away from interaction because the main principle of behaviorism is stimuli-response-reinforcement. The stimulus can be anything such as a picture which stimulates learners to talk about it, it might be a question motivating the learners to give an answer, and it might be a question which stimulates the learners to read a passage. The aim of reinforcement is to encourage the learner to repeat the same behavior in the future. It has nothing to do with what is happening in the mind of the learner; instead, it aims to motivate learners to repeat what they have received in the future. Therefore, there is a kind of interaction between the students and their teachers who provide them with reinforcement.

Therefore, interaction is an important aspect of the three theories in teaching language skills. Although every theory has a different aim for interaction, we cannot separate interactions or classify any interaction under one theory without the interference of the other theories. This makes the interrelationship between the three theories obvious because interaction between students and teachers might use the aspects of the three theories together. To put it simply, when the teacher interacts with a student through stimuli-response-reinforcement, this leads to improving cognitive abilities and building knowledge at the same time.

\section{Teaching Following the Integrated Teaching Model}

M-Language Teaching Model does not neglect the main role of each theory; however, it concentrates on the strength of each theory and integrates the three theories together for a better language teaching process. Ertmer and Newby (2013) gave guidelines for teaching through behaviorism, cognitivism and constructivism which are discussed below.

The goal of behaviorism is to help students get the desired response for the target stimulus, and this can be achieved through providing the students with opportunities to practice for the purpose of giving the proper response. Students should start from the easy and move to difficult skills and this is done through the assessment of the teacher. In terms of cognitivism, it emphasizes the active participation of learners in the learning process so that they become able to organize knowledge and make connections with previously learned knowledge. Besides, constructivism emphasizes on the context and the ability of the learner to manipulate the received information and use it in different contexts. Also, students can go beyond the instructions of the teachers using their own understanding (Ertmer \& Newby, 2013).

Accordingly, the process of teaching using the integrated teaching model starts with constructivism followed by cognitivism and behaviorism comes last. In constructivism, the teacher can start by presenting the skill intended to be taught in the class, and students can go to the tutorials and the details of the skills. The goal is to help 
students construct their knowledge and conceptualize the ideas in the context of the lesson and relate it to the knowledge which they have gained before. Different strategies can be used such as explaining the lesson to the students followed by a class discussion. In addition, some students can make presentations about the topic or the skill and discuss their ideas with the other students. Generally, students might not be able to practice the taught skill or face difficulties because they lack the basic knowledge concerning this skill. It is the role of the teacher to help the students build a strong knowledge about the skill before they move to practice. By providing the basics of a specific skill in reading, writing, speaking or listening to students, they will have the theoretical side of the skill and they will be ready to practice it.

Using the elements of cognitivism will support what the students have gained from the first stage. That is, first the students construct their knowledge which is related to constructivism, and then they move to self-monitoring and organization of ideas which is related to cognitivism. During practice, different things are required which include the activation of the knowledge which they have gained at the beginning of the lesson and the linguistic knowledge as students must supervise themselves and monitor their learning. They need to link the different parts of knowledge, or the new experience, with the previous knowledge by recalling the skills in order to improve their learning by finding the most effective method to deal with the taught skill. After constructing knowledge, learners should be cognitively ready to move to the practice the skill in real exercises. Cognitivism is interlaced with constructivism and behaviorism. That is, during the discussion of the skill at the beginning of the class, students can organize their knowledge and monitor their input according the ideas generated by the teacher or the other students. The input will be linked with the existing knowledge in order to monitor the process of learning. When it comes to practice with behaviorism, students also can recall the actual practice which they have performed before. Previous experience will guide of learners to avoid previous mistakes and use the proper skills and strategies. There is, therefore, a kind of monitoring during the first and the third stage of the model which is the essence of cognitivism.

Behaviorism comes last which brings the two previous stages to the actual practice. There is a stimulus and this stimulus can be skill or topic in any skill. Students have to respond to this stimulus which is the practical side of the skill. Students might study a specific skill such as finding the main idea in a reading passage. First, they have received the theoretical background of the skill and came to know how to deal with such questions theoretically, and they have constructed sufficient knowledge about the skill. After that they organize their ideas and link it to the previous experience in order to find the most effective method to deal with the skill. Then drills bring the two stages to the actual practice. An important point in the stage of behaviorism is that different drills are important to shape learners' skills and help them reach to problem solving depending on themselves. Reinforcement should be part and parcel of the practice in order to encourage students to keep the effort up. Extrinsic motivation from the side of the teacher is considered a kind of reinforcement for students to keep improving their skills and repeat the correct answers in the future.

It is clear that interaction is essential during the theoretical phase and the practical phase. This makes the three theories interlaced with each other because interaction is a part of the whole process, and it cannot be classified under one theory only.

According to Funk (2012), there should be a balance between input and output in the process of teaching a second or foreign language. This model provides the theoretical input for the students and stimulates them to express their understanding and practice to get feedback to reinforce their learning. Thus, the balance between the theoretical understanding and the practical application of the skill to be taught is essential in this model. The proposed model is illustrated in Figure 1 below. 


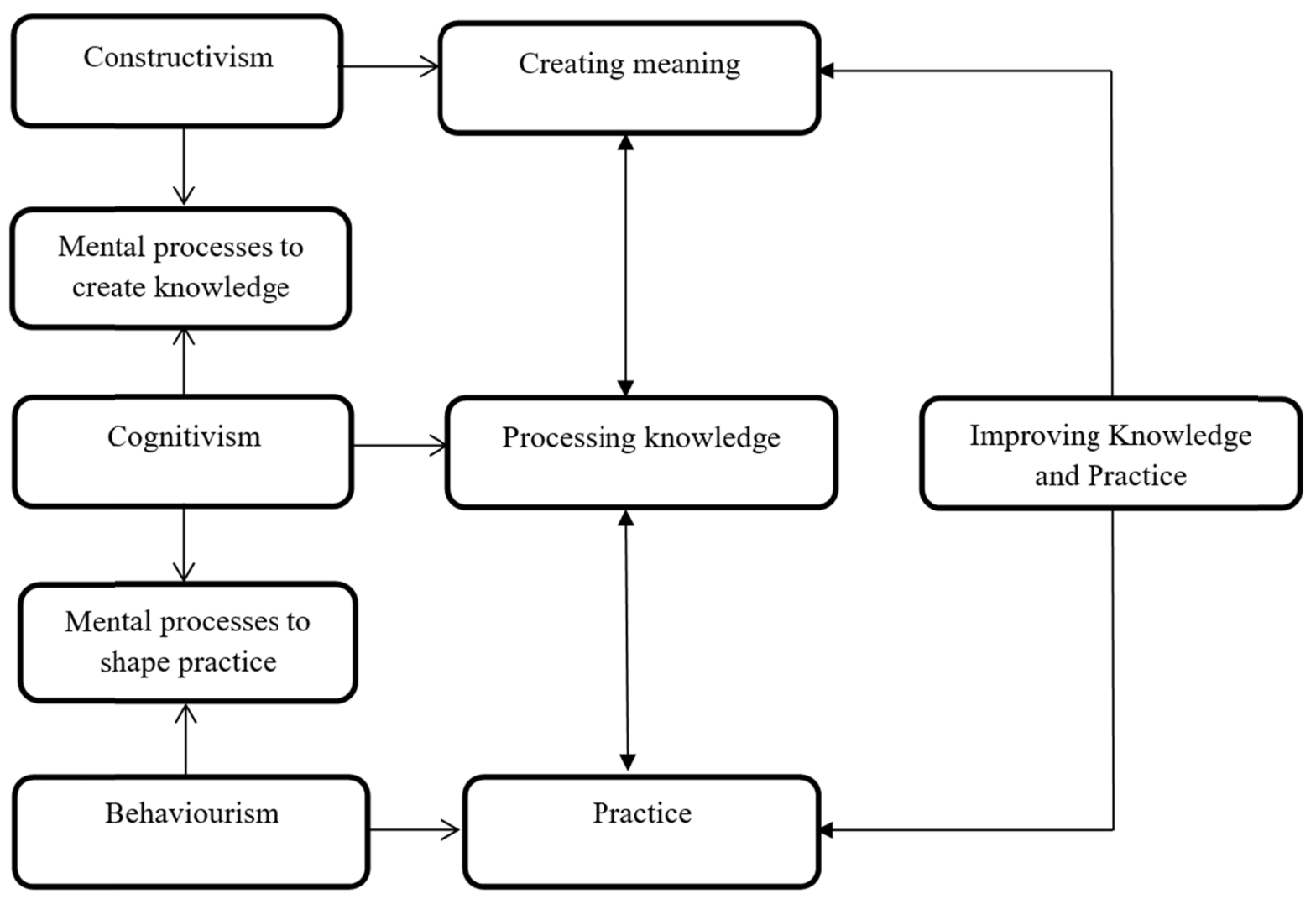

Figure 1. M-language teaching model

\section{Conclusion}

Previous literature did not account for an integrated model that combines different theories in the process of language teaching and learning. This paper suggests an integrated teaching model which combines different theories, namely behaviourism, cognitivism, and constructivism in the process of teaching language skills. The idea of this model is that teaching language skills can be divided into two phases. The first phase is the theoretical part and the second phase is the practical part. In the theoretical part, the teacher can depend on constructivism to help students build their knowledge about the skill. The second phase, which is practice, depends on behaviourisms as students need many exercises to master the skill. The link between these two processes is cognitivism since students need to create meaning and improve their understanding about the skills which involves mental processes. Also, practice is associated with cognitivism since practice activates all the linguistic knowledge which also requires mental processes. This model shows that the three theories are related and complete each other. Taking the aspects of each theory into consideration will help the teacher make a balance between theory and practice utilising the strength of each theory. Besides, this model engages the students in learning atmosphere because linking between the theoretical understanding and practice will ensure mastering the skills from the side of the students. More importantly, this model gives a better understanding for the learning theories and puts them in the context of teaching language skills. This model can be used as a framework for teaching language skills as it will help the researchers to provide a better and an in-depth explanation for the process teaching.

\section{References}

Allison, D. (2004). Changing understandings of classroom practices. Electronic Journal of Foreign Language Teaching, 1(1), 5-13.

Brown, H. D. (2007). Principles of language learning and teaching. New York: Pearson.

Chomsky, N. (1959). A review of BF Skinner's Verbal Behavior. Language, 35(1), 26-58. https://doi.org/10.2307/411334

Ertmer, P. A., \& Newby, T. J. (1993). Behaviorism, cognitivism, constructivism: Comparing critical features from an instructional design perspective. Performance Improvement Quarterly, 6(4), 50-72. 
https://doi.org/10.1111/j.1937-8327.1993.tb00605.x

Funk, H. (2012). Four models of language learning and acquisition and their methodological implications for textbook design. Electronic Journal of Foreign Language Teaching, 9(1), 298-311.

Hoover, W. A. (1996). The practice implications of constructivism. SEDL Letter, 9(3), 1-2.

Hutchinson, T., \& Waters, A. (1987). English for Specific Purposes: A Learning-Centered Approach. Cambridge: CUP.

Jonassen, D. H. (1991). Objectivism versus constructivism: Do we need a new philosophical paradigm? Educational Technology Research and Development, 39(3), 5-14. https://doi.org/10.1007/BF02296434

Jordan, A. (2008). Approaches to Learning. New York: Open University Press.

Kirschner, P. A., Sweller, J., \& Clark, R. E. (2006). Why minimal guidance during instruction does not work: An analysis of the failure of constructivist, discovery, problem-based, experiential, and inquiry-based teaching. Educational Psychologist, 41(2), 75-86. https://doi.org/10.1207/s15326985ep4102_1

Lado, R. (1957). Linguistics Across Cultures; Applied Linguistics for Language Teachers (With a Foreword by Charles C. Fries). University of Michigan press.

McLaughlin, B. (1989). Theories of second-language learning. Arnold.

McLeod, S. A. (2015). Cognitive Psychology. Retrieved March 12, 2017, from $\mathrm{http}: / /$ www.simplypsychology.org/cognitive.html

Mergel, B. (1998). Instructional design and learning theory. Retrieved April 4, 2019, from $\mathrm{http} / / /$ citeseerx.ist.psu.edu/viewdoc/download?doi=10.1.1.645.7122\&rep=rep1\&type=pdf

Mugny, G., \& Doise, W. (1978). Socio - cognitive conflict and structure of individual and collective performances. European Journal of Social Psychology, 8(2), 181-192. https://doi.org/10.1002/ejsp.2420080204

Mvududu, N., \& Thiel-Burgess, J. (2012). Constructivism in practice: The case for English language learners. International Journal of Education, 4(3), 108. https://doi.org/10.5296/ije.v4i3.2223

Nor, N. F. M., Azman, H., \& Hamat, A. (2013). Investigating students' use of online annotation tool in an online reading environment. 3L: Language, Linguistics, Literature, 19(3).

Piaget, J., \& Inhelder, B. (1969). The psychology of the child. New York: Basic Books.

Skinner, B. F. (1957). Verbal behavior. Copley Publishing Group. https://doi.org/10.1037/11256-000

Skinner, B. F. (2014). Verbal behavior. BF Skinner Foundation.

Spiro, R. J., Feltovich, P. J., Jacobson, M. J., \& Coulson, R. L. (1991). Knowledge representation, content specification, and the development of skill in situation-specific knowledge assembly: Some constructivist issues as they relate to cognitive flexibility theory and hypertext. Educational Technology, 31(9), 22-25.

Thompson, A. D., Simonson, M. R., \& Hargrave, C. P. (1992). Educational technology: A review of the research. Association for educational communications and technology.

Vygotsky, L. S. (1978). Mind in society. Cambridge: Harvard University Press.

Weegar, M. A., \& Pacis, D. (2012). A Comparison of Two Theories of Learning-Behaviorism and Constructivism as applied to Face-to-Face and Online Learning. In Proceedings E-Leader Conference, Manila.

Xiangui, Z. (2005). Learning theories and second language learning. CELEA Journal, 28(5), 120-127.

Yassin, A. A., Razak, N. A., \& Maasum, T. N. R. T. M. (2018). Cooperative Learning: General and Theoretical Background. Advances in Social Sciences Research Journal, 5(8).

\section{Copyrights}

Copyright for this article is retained by the author, with first publication rights granted to the journal.

This is an open-access article distributed under the terms and conditions of the Creative Commons Attribution license (http://creativecommons.org/licenses/by/4.0/). 